ORIGINAL ARTICLE

\title{
Factors relating to the infant's last sleep environment in sudden infant death syndrome in the Republic of Ireland
}

\author{
C McGarvey, M McDonnell, A Chong, M O'Regan, T Matthews
}

Arch Dis Child 2003;88:1058-1064

See end of article for authors' affiliations

.....................

Correspondence to: Dr C McGarvey, The National Sudden Infant Death Register, George's Hall, The Children's Hospital, Temple St,

Dublin 1, Republic of Ireland; isidansr@tsch.ie

Accepted 23 April 2003

\begin{abstract}
Aim: To identify risk factors for sudden infant death syndrome (SIDS) in the sleeping environment of Irish infants.

Methods: A five year population based case-control study with parental interviews conducted for each case and three controls matched for age, place of birth, and last sleep period. A total of 203 SIDS cases and 622 control infants born 1994-98 were studied.

Results: In a multivariate analysis, co-sleeping significantly increased the risk of SIDS both as a usual practice (adjusted OR $4.31 ; 95 \% \mathrm{Cl} 1.07$ to 17.37 ) and during the last sleep period (adjusted OR 16.47; $95 \% \mathrm{Cl} 3.73$ to 72.75 ). The associated risk was dependent on maternal smoking (OR $21.84 ; 95 \% \mathrm{Cl} 2.27$ to 209.89 ), and was not significant for infants who were $\geqslant 20$ weeks of age (OR $2.63 ; 95 \% \mathrm{Cl} 0.49$ to 70.10 ) or placed back in their own cot/bed to sleep (OR $1.07 ; 95 \% \mathrm{Cl} 0.21$ to 5.41 ). The use of pillows, duvets, and bedding with tog value $\geqslant 10$ were not significant risk factors when adjusted for the effects of confounding variables, including maternal smoking and social disadvantage. However, the prone sleeping position remains a significant SIDS risk factor, and among infants using soothers, the absence of soother use during the last sleep period also significantly increased the SIDS risk (OR 5.83; $\mathrm{Cl} 2.37$ to 14.36).

Conclusion: Co-sleeping should be avoided in infants who are $<20$ weeks of age, or whose mothers smoked during pregnancy. The prone position remains a factor in some SIDS deaths, and the relation between soother use and SIDS is a complex variable requiring further study.
\end{abstract}

$\mathrm{D}$ espite dramatic reductions in the rates of sudden infant death syndrome (SIDS) following intervention campaigns, based on the epidemiological association between SIDS and the prone sleeping position, SIDS remains the leading cause of infant death in developed countries. In Ireland the SIDS rate has declined from 2.0 (1980-93 inclusive) to 0.8 per 1000 live births (1994-2000 inclusive) and now accounts for four in every ten infant deaths in the post-neonatal period. ${ }^{1}$ Encouraged by this remarkably successful intervention campaign, additional epidemiological studies, from different countries, have sought to identify other modifiable risk factors for SIDS; they have included sociodemographic factors, factors relating to pregnancy and birth, parenting and lifestyle practices, as well as factors relating to the infant's last sleep period.$^{2-7}$

Several studies, examining the infant's last sleep period, have shown an increased risk of SIDS associated with parent-infant co-sleeping. ${ }^{3-11}$ However, in many countries, including Hong Kong, China, and Japan, where the SIDS rates are among the lowest in the world, parent infant cosleeping is the most common sleeping arrangement. ${ }^{12-16}$ It has also been suggested that co-sleeping may increase infant arousability, minimise prone sleep positioning, and promote breast feeding, and might therefore serve as a protective factor for SIDS, ${ }^{17}{ }^{18}$ although the American Academy of Pediatrics and the National Institute of Child Health and Human Development have stated that bed sharing does not reduce the risk of SIDS. ${ }^{19}$ It is likely that infant-parent cosleeping results in complex interactions with other factors related to the infant's sleeping environment. Such factors may vary from one individual to the next and from country to country, and may account for the conflicting and contradictory messages in the published literature. The objective of this study was to examine the role of factors relating to the infant's sleeping environment, including co-sleeping, as risk factors for SIDS in Irish infants.

\section{METHODS}

A five year case control study was conducted using data on infants who died from SIDS in the Republic of Ireland between 1 January 1994 and 31 December 1998. All sudden unexpected infant deaths in the Republic of Ireland are reported to the Irish Sudden Infant Death Association's National SIDS Register within 48 hours of the infant's death. SIDS is defined as the sudden death of an infant which was unexpected by history and where a thorough postmortem examination failed to show an adequate cause of death. Ascertainment of cases was when SIDS was the diagnosis used on the death certificate after a postmortem examination. Death certificates were made available by the central statistics office, facilitated by the Department of Health and Children, and postmortem reports were also forwarded to the SIDS Register by the coroners, allowing complete ascertainment of cases. Four control infants were selected randomly from the birth register for each case matched for date of birth and geographical location. Parents of both cases and controls were invited by letter to participate in a home interview designed to collect information on sociodemographics, mother's pregnancy, the baby's birth and medical history, home environment, lifestyle and parenting practices, and details relating to the infant's last 48 hours and last sleep period. A corresponding reference sleep period was used for controls. Parents were interviewed by one of two researchers in their homes within six weeks of their baby's death. The average time interval between notification and interview was 5.7 weeks for cases and 5.9 weeks for controls.

Statistical analysis of data was carried out using STATA, version 6. All data were analysed by multiple conditional 
logistic regression allowing for matching. Differences between cases and controls were expressed using odds ratios and $95 \%$ confidence intervals. Initially each variable was examined on its own in a univariate analysis, after which it was adjusted for the potential confounding effects of other variables in a multivariate analysis. In order to control for any bias introduced due to the fact that control infants were older than SIDS cases at the time of interview, all analysis relating to the last sleep period was adjusted for infant age (age of death for SIDS cases and age at interview for controls). All multivariate analysis included a social disadvantage index, scoring $0-5$ ( 5 being most disadvantaged) which was devised by adding a score of one for each of the following: having a medical card (a low income based free health service entitlement), being in rented accommodation (excluding private), not having a car, both parents being unemployed, and mother on social welfare. $\mathrm{Z}$ scores of weight for gestation were adjusted for the effects of gender and parity. Computer generated norms compiled in the UK were used, as norms for Ireland were not available. ${ }^{20}$ In order to investigate the prevalence of various risk factors among families who choose to co-sleep and those families who do not co-sleep, categorical data on co-sleeping was compared with data from infants sleeping alone using $\chi^{2}$ analysis. Co-sleeping was defined as any shared sleeping arrangement of an infant with any parent(s)/relative in or on a bed/sofa/armchair. The variable "history of illness" was a categorical variable referring to any illness the infant had suffered since birth $(0=$ none, $1=$ yes $)$.

\section{RESULTS}

\section{Sample size and response rate}

A total of 203 SIDS cases and 622 control infants were included in this study. This corresponded to $81 \%$ of SIDS families. An average of three control families per case agreed to participate, resulting in a response rate of $77 \%(n=622)$. The majority of cases (73\%) occurred during the night-time sleep between 22:00 and 08:00.

\section{Risk factors associated with the infant's sleep environment during the last/reference sleep period}

Table 1 lists variables relating to the infant's sleep environment during the last/reference sleep period. Each of the variables included in the table are dichotomous variables, with the exception of a single variable for prone and side sleeping in which each was compared with infants placed supine. Infants who were found in the prone position but had not been placed to sleep in this position were referred to as being "secondary prone". With the exception of the variable for secondary prone position the unadjusted odds ratios for each of the variables listed in table 1 proved to be statistically significant. Eleven per cent of SIDS cases were found in the prone position despite the fact that they were not placed in this position. Using "infants who were neither placed nor found prone" as a reference group, the unadjusted odds ratio (UOR) for infants who were found in the secondary prone position was 2.07 , but this did not quite reach statistical significance $(95 \%$ CI 0.99 to $4.32 ; p=0.052)$. Infants who were usually placed in a non-prone position to sleep but were placed prone on the night of the last sleep were referred to as "unaccustomed prone". Eight per cent of SIDS cases were in an unaccustomed prone position during the last sleep period compared with $0.2 \%$ of control infants during a corresponding reference sleep period. Low numbers in the control group prevented further statistical analysis of this variable.

On multivariate analysis, adjusting for the effects of maternal age, education, smoking and drinking during pregnancy, social disadvantage, $\mathrm{z}$ scores for weight by gestation, whether breast feeding was initiated at birth, baby having a history of illness during his/her lifetime, crying/colic problems, symptoms in the last 48 hours prior to last/ reference sleep, use of pillows, tog of bed coverings $\geqslant 10$, use of duvets, change in routine soother use, and use of prone position during the last/reference sleep, only use of the prone sleeping position, co-sleeping, and absence of routine soother use remained statistically significant.

\section{Co-sleeping}

More cases than controls were found co-sleeping with their parents or another adult in the parental/other's bed or on a sofa or armchair during the last sleep period $(44 \%(n=68)$ of cases; $5 \%(\mathrm{n}=32)$ of controls). Table 2 presents these data. Univariate analysis of these data revealed a significant odds ratio of 7.34 ( $95 \%$ CI 1.54 to $34.92 ; \mathrm{p}<0.01$ ), indicating that co-sleeping increases the SIDS risk by a factor of seven. This figure was increased to 16.47 (95\% CI 3.72 to $72.75 ; \mathrm{p}<0.001$ ) when adjusted for the potential confounders listed previously. Six cases were found co-sleeping on a sofa or armchair (table 2). Estimation of the risk associated with cosleeping specifically on a sofa/armchair was not possible due to the lack of any control infants who co-slept on a sofa/ armchair.

The risk associated with usual practice of co-sleeping was lower than for co-sleeping during the last sleep period: unadjusted odds ratio (UOR) 5.79 (95\% CI 3.31 to 10.13) and adjusted odds ratio (AOR) 4.31 (95\% CI 1.07 to 17.37 ). Nineteen per cent of cases who were co-sleeping at the time

Table 1 Variables associated with the infants' last/reference sleep as risk factors for SIDS

\begin{tabular}{|c|c|c|c|c|c|c|c|c|c|c|}
\hline \multirow[b]{2}{*}{ Variable } & \multicolumn{2}{|c|}{ Cases } & \multicolumn{2}{|c|}{ Controls } & \multicolumn{3}{|c|}{ Univariate analysis* } & \multicolumn{3}{|c|}{ Multivariate analysis } \\
\hline & $n$ & $\%$ & $\mathbf{n}$ & $\%$ & $\overline{O R}$ & $95 \% \mathrm{Cl}$ & p value & $\overline{O R}$ & $95 \% \mathrm{Cl}$ & $p$ value \\
\hline Placed prone & 19 & 12 & 15 & 2 & 8.28 & 3.43 to 19.98 & $<0.001$ & 11.47 & 1.24 to 106.06 & $<0.05$ \\
\hline Placed in side position & 68 & 44 & 230 & 37 & 1.76 & 1.16 to 2.66 & $<0.001$ & 2.38 & 0.69 to 8.21 & 0.17 \\
\hline Co-sleeping & 68 & 44 & 32 & 5 & 7.34 & 1.54 to 34.92 & $<0.01$ & 16.47 & 3.73 to 72.75 & $<0.001$ \\
\hline Use of pillows & 68 & 44 & 73 & 12 & 7.03 & 4.27 to 11.58 & $<0.001$ & 1.10 & 0.30 to 4.01 & 0.87 \\
\hline Tog of coverings $\geqslant 10$ & 101 & 67 & 310 & 50 & 2.34 & 1.53 to 3.58 & $<0.001$ & 0.93 & 0.35 to 2.46 & 0.89 \\
\hline Use of duvets & 81 & 53 & 118 & 19 & 5.27 & 3.38 to 8.22 & $<0.001$ & 1.32 & 0.41 to 4.15 & 0.63 \\
\hline $\begin{array}{l}\text { Absence of routine } \\
\text { soother use }\end{array}$ & 70 & 47 & 119 & 19 & 4.53 & 2.92 to 7.01 & $<0.001$ & 5.86 & 2.37 to 14.36 & $<0.01$ \\
\hline Secondary prone position & 17 & 11 & 24 & 4 & 2.07 & 0.99 to 4.32 & 0.052 & na & na & na \\
\hline Unaccustomed prone & 18 & 11 & 24 & 4 & 2.07 & 0.77104 .02 & & na & na & na \\
\hline position & 12 & 8 & 1 & 0.2 & $\dagger$ & $\dagger$ & $\dagger$ & $\dagger$ & $\dagger$ & $\dagger$ \\
\hline
\end{tabular}

Adjusted for maternal age, education, smoking during pregnancy, social disadvantage, $\mathrm{z}$ scores for weight by gestation, whether breast feeding initiated at birth, baby being ill, crying/colic problems, symptoms in $48 \mathrm{~h}$ prior to last/reference sleep, and other variables listed in table (excluding variables for secondary and unaccustomed prone). *Adjusted for infant age.

tOdds ratios (OR) not available.

na, analysis not applicable due to non-significance of unadjusted odds ratio. 
Table 2 Infant-parent co-sleeping and the risk of SIDS

\begin{tabular}{|c|c|c|c|c|c|c|c|c|c|c|}
\hline \multirow[b]{2}{*}{ Co-sleeping routine } & \multicolumn{2}{|c|}{ Cases } & \multicolumn{2}{|c|}{ Controls } & \multicolumn{3}{|c|}{ Univariate $†$} & \multicolumn{3}{|c|}{ Multivariate* $^{*}$} \\
\hline & n & $\%$ & $n$ & $\%$ & OR & $95 \% \mathrm{Cl}$ & p value & OR & $95 \% \mathrm{Cl}$ & $\mathrm{p}$ value \\
\hline \multicolumn{11}{|l|}{ Usual practice (night) } \\
\hline No & 114 & 73 & 587 & 95 & ref & & & ref & & \\
\hline Yes & 42 & 27 & 33 & 5 & 5.79 & 3.31 to 10.13 & $<0.001$ & 4.31 & 1.07 to 17.37 & $<0.05$ \\
\hline \multicolumn{11}{|c|}{ Last/reference sleep period (a) } \\
\hline No & 87 & 56 & 587 & 95 & ref & & & ref & & \\
\hline Yes & 68 & 44 & $32 \ddagger$ & 5 & 7.34 & 1.54 to 34.92 & $<0.01$ & 16.47 & 3.72 to 72.75 & $<0.001$ \\
\hline \multicolumn{11}{|c|}{ Bedsharing during last sleep period (b) } \\
\hline No bedsharing & 76 & 50 & 483 & 78 & Ref & & & ref & & \\
\hline Put back in cot & 23 & 15 & 106 & 17 & 1.07 & 0.21 to 5.41 & 0.93 & 1.29 & 0.41 to 3.95 & 0.66 \\
\hline $\begin{array}{l}\text { Bedsharing entire sleep } \\
\text { period }\end{array}$ & 47 & 31 & 31 & 5 & 5.25 & 1.09 to 25.25 & $<0.05$ & 9.28 & 1.69 to 50.90 & $<0.05$ \\
\hline $\begin{array}{l}\text { Co-sleeping on } \\
\text { sofa/armchair }\end{array}$ & 6 & 4 & 0 & 0 & $\S$ & $\S$ & $\S$ & $\S$ & $\S$ & $\S$ \\
\hline
\end{tabular}

*Adjusted for maternal age, education, smoking and drinking during pregnancy, social disadvantage, $\mathrm{z}$ scores for weight by gestation, whether breast feeding was initiated at birth, baby being ill, crying/colic problems, symptoms in $48 \mathrm{~h}$ prior to last/reference sleep, tog of bed covering $\geqslant 10$, use of pillows, duvets, prone position, and absence of routine soother use during the last/reference sleep period.

†Adjusted for infant age at death/interview.

flnformation not available on one infant. Difference in number of co-sleepers during the last sleep between (a) and (b) due to the inclusion in (a) only of infants who were co-sleeping specifically at the time of death/awakening, while (b) refers to all infants who were co-sleeping during this sleep period, including those who were placed back in their own cot/bed prior to or following being in adults' bed/sofa/armchair.

$\S$ Odds ratio (OR) not available due to the lack of any control infants who co-slept on sofas/armchairs.

of death were not accustomed to this practice, in comparison with $1 \%$ of controls (data not shown).

\section{Bed sharing}

Subjects that were co-sleeping on sofa/armchairs were excluded from analysis relating to bed sharing due to confounding effects of pillow use, soft bedding etc. Of all cases who had bed shared with their parents/others during the last sleep period, $31 \%(n=47)$ spent the duration of the sleep period in the adult's bed, compared with only 5\% of control babies (table 2). In a multivariate analysis, bed sharing for the entire sleep period increased the SIDS risk by a factor of 9 (OR 9.28; 95\% CI 1.69 to 50.90; $p<0.05$ ) but we found no associated risk when the infant was placed back in their own cot/bed to sleep (UOR 1.07; 95\% CI 0.21 to 5.41 ). Figure 1 shows the reasons stated by parents for bed sharing with their babies at the time of the last/reference sleep. Most control infants (55\%) were brought into bed for the purpose of feeding, while only $5 \%$ of cases were bed sharing for this purpose. The most common reason stated by case parents was that bed sharing was the usual pattern of sleeping arrangement (54\%). Another $28 \%$ of cases were brought into bed "to settle" or "for comfort". Only $11 \%$ of control infants who bed shared during a reference sleep period were doing so because it was the usual pattern. The risk associated with bed sharing was not significant for infants $\geqslant 20$ weeks of age (UOR 2.63 (95\% CI 0.99 to 70.10 ) versus 4.99 (95\% CI 1.02 to 24.54)) if the infant was less than 20 weeks old (table 3 ).

Table 4 outlines the proportion of case babies that were cosleeping when they died and their proximity to the parent(s)/

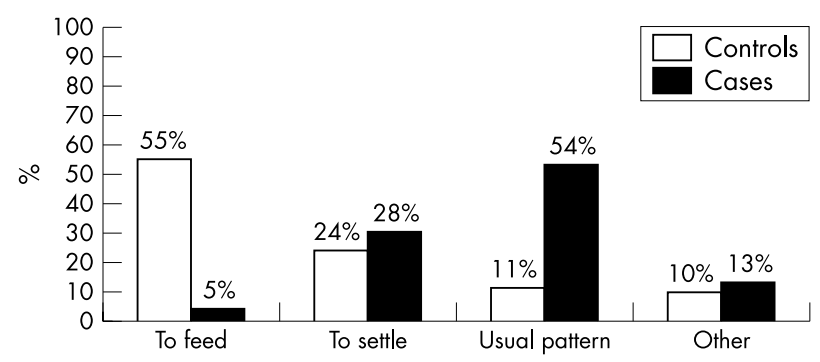

Figure 1 Reasons stated for bed sharing during the last/reference sleep period. other sharing the bed/sofa/armchair. Most (51\%) were found positioned next to one parent. Infants who had been cosleeping with their father on a couch/armchair were found in the crook of father's arm, prone on father's chest/tummy, or "squashed" between father and back of the couch/armchair.

\section{Prevalence of risk factors among co-sleeping and non co-sleeping infants}

In order to examine the factors which might influence the choice of sleeping arrangement and risk associated with cosleeping, an analysis of the prevalence of various risk factors among both co-sleeping and non co-sleeping infants (both cases and controls) was carried out. This analysis revealed that infants who co-slept were more likely to have used duvets and pillows and to have had bed coverings with a tog $\geqslant 10$ than those who slept alone (table 5). They were also more likely to be from socially disadvantaged families ( $43 \% \mathrm{v}$ $18 \% ; \mathrm{p}<0.001)$ and to have mothers who smoked during pregnancy $(65 \% \vee 32 \%, \mathrm{p}<0.001)$. In addition, co-sleeping infants who routinely used a soother were significantly more likely than non co-sleeping infants to be missing this soother during the last/reference sleep period ( $36 \% \vee 23 \%$; $<<0.01$ ). Co-sleeping infants were also more likely to have had a history of illness during their lifetime $(56 \% v 32 \%, \mathrm{p}<0.001)$ and to have had symptoms in the 48 hours prior to the last/ reference sleep $(39 \% \vee 28 \%, \mathrm{p}<0.05)$. While a higher proportion of co-sleepers were placed and found in the prone position than non co-sleepers, this difference did not prove to be statistically significant. Breast feeding rates were not different for co-sleepers and those sleeping alone (39\% v 42\%; $\mathrm{p}=0.56$ ).

\section{Interactions between co-sleeping and other risk factors}

The interaction of the co-sleeping variable with other risk factors was also examined and results are listed in table 6 . Thirty nine per cent of cases were co-sleeping and had mothers who smoked during pregnancy compared with only $1 \%$ of controls (table 6 ). Results of logistic regression analysis show that the interaction between the variables for cosleeping and maternal smoking is statistically significant, indicating that the effect of co-sleeping is dependent on maternal smoking (UOR 21.84, 95\% CI 2.27 to 209.89; AOR $29.23,95 \%$ CI 2.69 to 316.78 ). Further analysis of these data 
Table 3 Analysis of bed sharing according to infants' age

\begin{tabular}{|c|c|c|c|c|c|c|c|c|c|c|}
\hline \multirow[b]{2}{*}{ Variable } & \multicolumn{2}{|c|}{ Cases } & \multicolumn{2}{|c|}{ Controls } & \multicolumn{3}{|c|}{ Univariate analysis $†$} & \multicolumn{3}{|c|}{ Multivariate analysis* } \\
\hline & $n$ & $\%$ & $n$ & $\%$ & OR & $95 \% \mathrm{Cl}$ & $p$ value & OR & $95 \% \mathrm{Cl}$ & $p$ value \\
\hline No bed sharing & 93 & 60 & 587 & 95 & ref & & & ref & & \\
\hline Bed sharing/infant $<20$ wk & 51 & 33 & 18 & 3 & 4.99 & 1.02 to 24.54 & $<0.05$ & 16.86 & 6.27 to 45.30 & $<0.001$ \\
\hline Bed sharing/infant $\geqslant 20 \mathrm{wk}$ & 11 & 7 & 14 & 2 & 2.63 & 0.99 to 70.10 & $<0.56$ & 2.80 & 0.71 to 11.01 & 0.14 \\
\hline
\end{tabular}

*Adjusted for maternal age, education, social disadvantage, and other variables relating to the infant's last sleep period.

†Adjusted for infant age at death/interview.

revealed that without controlling for other variables, the odds ratio for co-sleeping infants whose mothers did not smoke was statistically significant and varied between 1.42 and 13.91. However, the risk associated with co-sleeping was higher for infants whose mothers smoked, the odds ratio varying between 13.21 and 711.69.

Significant interactions between co-sleeping and variables for "history of illness since birth" and "initiation of breast feeding at birth" indicate that the risk associated with cosleeping is influenced by both these factors also. However, this analysis requires further investigation.

\section{Use of soothers}

Soother use was a complex variable with univariate analysis of the data suggesting that usual use of a soother significantly increased the risk of SIDS (OR 1.95; 95\% CI 1.25 to 3.06; $\mathrm{p}<0.01)$ while use of a soother in the last sleep period emerged as a protective factor (UOR $0.34 ; 95 \%$ CI 0.22 to $0.50 ; \mathrm{p}<0.001)$. Table 7 presents these results. On multivariate analysis the odds ratio for use of a soother during the last sleep but not for usual use, remained statistically significant (OR $0.10 ; 95 \%$ CI 0.03 to 0.31 ). Further examination of the data showed that while $77 \%$ of cases habitually used a soother, only $30 \%$ did so on the night of the last sleep. Analysis of a new variable, examining the change in habitual soother use, revealed that babies who regularly used a soother while sleeping were at a significantly higher risk of SIDS if this soother was missing during the last/reference sleep period (UOR 4.53; 95\% CI 2.92 to $7.01 ; \mathrm{p}<0.001$ ). When adjusted for the potential confounding effects of the variables listed previously the odds ratio for this variable remained statistically significant (AOR 5.83; 95\% CI 2.37 to 14.36; $\mathrm{p}<0.001)$. Thus the variable, absence of routine soother use, was used in all analysis related to the infants' last sleep period.

\section{DISCUSSION}

The results of this study show that use of the prone sleep position, certain arrangements of co-sleeping, and the absence of routine soother use during the last sleep period significantly increase an infant's risk of SIDS. Other variables

Table 4 Location of SIDS infants found in parental bed

\begin{tabular}{llr}
\hline & \multicolumn{2}{l}{ Cases } \\
\cline { 2 - 3 } Location & $\mathbf{n}$ & $\%$ \\
\hline Next to one parent/adult & 37 & 51.4 \\
Between parents/adult & 24 & 33.3 \\
Other & 2 & 6.9 \\
On sofa/armchair with father/other & 6 & 8.3
\end{tabular}

"Other" includes: baby down in middle of bed along with mother $(n=1)$, in bed with mother and sibling $(n=1)$.

Infants who had been co-sleeping with their father on a couch or armchair were found in crook of father's arm $(n=3)$, prone on father's chest or tummy ( $n=1)$, or "squashed" between father and back of couch after being placed prone on father's chest or tummy $(n=2)$. relating to the infant's sleep environment, including the use of pillows, duvets, and bedding with a tog value of $\geqslant 10$ which were statistically significant in a univariate analysis did not prove to be significant risk factors for SIDS when adjusted for the effects of other confounding variables including maternal smoking during pregnancy and social disadvantage.

The risk associated with co-sleeping was dependent on whether or not the infant's mother smoked and was not significant for infants who were $\geqslant 20$ weeks of age. Similar findings have been reported in previous studies which have also found that infants found dead while co-sleeping were younger than the total SIDS population or non co-sleeping SIDS cases. ${ }^{5} 10^{1121}$ However, few studies have examined the role of co-sleeping in relation to the number of adults/siblings sharing the bed and their proximity to the infant. We found that in most cases the baby was located next to one adult (table 3 ). Unfortunately we did not have an appropriate reference group with which we could calculate odds ratios. It has been shown previously that the risk associated with cosleeping is similar irrespective of whether one or two parents shared the bed. ${ }^{10}$

Co-sleeping has been reported to promote and increase successful breast feeding, which in itself has been said to reduce the SIDS risk, ${ }^{7822-24}$ and in Norway co-sleeping was recommended to parents specifically in order to encourage breast feeding. ${ }^{11}$ However, we found no difference in the rate of breast feeding between infants who co-sleep and those who sleep on their own (table 5). A majority of the control parents in the study stated feeding purposes as the reason for bringing their baby into bed in contrast with only $5 \%$ of SIDS parents (fig 1). A majority of SIDS cases were bed sharing at the time of death because it was the usual sleeping arrangement. Our data show that bed sharing does not pose a risk if the infant is placed back in their own cot to sleep, as only infants who were bed sharing for the entire sleep period were at increased risk of SIDS. Thus bed sharing for the purpose of breast feeding would not increase the SIDS risk providing the baby is placed back in their own cot afterwards. Whether breast feeding actually serves as a protective factor to reduce the risk of SIDS remains a matter of debate since it is possible that breast feeding may in fact be a marker for socioeconomic status or other lifestyle factors such as maternal smoking. ${ }^{3} 924$

Co-sleeping infants were significantly more likely than non co-sleeping infants to have had a history of illness and to have had symptoms in the 48 hours prior to last/reference sleep (table 5). This raises the question of whether some babies are taken into the parental bed specifically due to the fact that they were ill and whether it is the actual illness rather than co-sleeping per se which is the cause of death. For this reason it is important to control for these variables when calculating the odds ratios for co-sleeping. Co-sleeping remained a significant risk when adjusted for any illness during the baby's lifetime and illness in the 48 hours prior to the infant's last sleep, indicating that co-sleeping poses a risk independent of these variables. It has previously been shown that mild illness was not associated with an increased risk of 
Table 5 Prevalence of risk factors among all co-sleeping and non co-sleeping infants during the last sleep period

\begin{tabular}{llcrc}
\hline Variable & Co-sleepers (\%) & Sleeping alone (\%) & $\chi^{2}$ & p value \\
\hline Placed prone & 8 & 4 & 3.54 & 0.06 \\
Found prone & 14 & 9 & 3.42 & 0.06 \\
Pillows used & 54 & 13 & 94.63 & $<0.001$ \\
Tog of bedding $\geqslant 10$ & 81 & 50 & 33.31 & $<0.001$ \\
Duvets used & 79 & 18 & 166.16 & $<0.001$ \\
Absence of routine soother use & 36 & 23 & 7.83 & $<0.01$ \\
Mother smoker & 65 & 32 & 40.46 & $<0.001$ \\
Breast feeding initiated at birth & 39 & 42 & 0.33 & 0.56 \\
Illness in last 48 h & 39 & 28 & 21.76 & $<0.05$ \\
History of illness since birth & 56 & 32 & 5.77 & $<0.001$ \\
Social disadvantage (3-5) & 43 & 18 & 35.31 & $<0.001$ \\
\hline Percentages refer to proportion of all subjects, including both cases and controls. & &
\end{tabular}

SIDS if the infant did not usually sleep prone, but was associated with a sixfold increase among infants who usually slept prone. ${ }^{25}$ A significant interaction between co-sleeping, and baby having a history of illness and whether breast feeding was initiated at birth, indicates that the risk associated with co-sleeping is influenced by these factors. Although further study of these interactions is required the negative odds ratios suggest that the co-sleeping risk is lower in these circumstances.

In this study co-sleeping was defined as any shared sleeping arrangement of an infant with any parent(s)/relative in or on a bed/sofa/armchair; six SIDS cases in total were found co-sleeping on sofas. Two studies have found that infants sleeping on sofas or makeshift bedding, with or without another adult, was particularly hazardous with higher odds ratios than for co-sleeping in an adult bed. ${ }^{26}{ }^{27}$ Nine per cent of babies (6/68) who were co-sleeping when found dead were doing so on a couch or sofa. Many of these were in the prone position or positioned either in the crook of the father's arm or wedged between the father and the back of the couch. However, the lack of any controls sleeping on sofas prevented us from analysing these data any further and estimating the risk associated with co-sleeping specifically on sofas/couches. Parental alcohol consumption or drug intoxication has been suggested as accounting for the increased risk from co-sleeping through accidental overlaying. However, there is insufficient evidence to support this interaction, and co-sleeping or bed sharing is still a significant risk among those infants where alcohol consumption was not a factor. ${ }^{9} 1028$

After adjusting for potential confounding factors, infants placed to sleep in the prone position for the last/reference sleep were 11 times more likely to die from SIDS in comparison with those placed supine. Side sleeping is also generally considered to be a risk due to the possibility of the infant turning onto his or her front. However, the risk associated with side sleeping became non-significant in a multivariate analysis. More co-sleeping than non co-sleeping infants were placed and found in the prone position during the last sleep period although this difference was not significant. This observation does not support the theory that co-sleeping may reduce the risk of SIDS by minimising prone sleeping. Flick et al have shown that bed sharers were twice as likely to be habitually placed prone. ${ }^{29}$ Of all the SIDS infants placed prone to sleep for the last sleep period, 63\% were unaccustomed to being in this position. Only one control infant during a corresponding reference sleep period was in an unaccustomed prone position and for this reason we were not able to evaluate the risk associated specifically with unaccustomed prone sleeping. However, previously published studies have shown an increased risk associated with being unaccustomed to the prone position. ${ }^{70}$ These data suggest that inexperience of prone sleeping would reduce an infant's ability to escape from potentially lethal situations. Eleven per cent of SIDS cases were found in the secondary prone position, but this was not statistically significant. This is possibly due to the fact that most of these infants were older (data not shown) and perhaps accustomed to changing position during sleep.

Previously reported case-control studies have reported a protective effect of soother usage with regard to SIDS. ${ }^{11} 3132$ In this study more SIDS cases than controls habitually used a soother. However, $47 \%$ of these babies did not have their soother on the night they died. Infants who usually used a soother and did not have it during the last/reference sleep were almost six times more at risk than regular users who did have it (table 7). Thus it appears that rather than conferring a protective effect, it is in fact the absence of habitual soother

Table 6 Interaction between co-sleeping variable and other risk factors

\begin{tabular}{|c|c|c|c|c|c|c|c|}
\hline \multirow[b]{2}{*}{ Risk factor } & \multicolumn{2}{|c|}{ Cases } & \multicolumn{2}{|c|}{ Controls } & \multicolumn{3}{|c|}{ Interaction with co-sleeping } \\
\hline & $\bar{n}$ & $\%$ & $\bar{n}$ & $\%$ & $\overline{\mathrm{OR}}$ & $95 \% \mathrm{Cl}$ & p value \\
\hline Found prone & 11 & 8 & 3 & 0.5 & 0.21 & 0.38 to 1.20 & 0.08 \\
\hline Placed in prone position & 8 & 5 & 0 & 0 & $*$ & * & * \\
\hline Pillows used & 44 & 29 & 9 & 1.5 & 0.55 & 0.15 to 1.94 & 0.35 \\
\hline Use of duvets & 53 & 35 & 25 & 4 & 0.44 & 0.10 to 1.90 & 0.28 \\
\hline Tog of bedding $\geqslant 10$ & 56 & 37 & 23 & 4 & 1.10 & 0.28 to 4.25 & 0.88 \\
\hline Absence of routine soother use & 30 & 20 & 5 & 0.8 & 0.51 & 0.13 to 2.01 & 0.34 \\
\hline Mother smoking during pregnancy & 61 & 39 & 4 & 1 & 21.84 & 2.27 to 209.89 & $<0.01$ \\
\hline Breast feeding initiated at birth & 13 & 8 & 26 & 4 & 0.41 & 0.03 to 0.80 & $<0.05$ \\
\hline History of illness since birth & 43 & 28 & 12 & 2 & 0.30 & 0.09 to 0.97 & $<0.05$ \\
\hline Symptoms in $48 \mathrm{~h}$ prior to death/awakening & 28 & 18 & 11 & 2 & 0.46 & 0.11 to 1.84 & 0.28 \\
\hline Social disadvantage (3-5) & 40 & 26 & 3 & 0.5 & 0.68 & 0.15 to 3.04 & 0.61 \\
\hline
\end{tabular}

Proportions refer to those subjects who were positive for both co-sleeping and the risk factor.

*Odds ratios not available. 
Table 7 Use of soothers and the risk of sudden infant death syndrome

\begin{tabular}{|c|c|c|c|c|c|c|c|c|c|c|}
\hline \multirow[b]{2}{*}{ Soother used } & \multicolumn{2}{|c|}{ Cases } & \multicolumn{2}{|c|}{ Controls } & \multicolumn{3}{|c|}{ Univariate analysis } & \multicolumn{3}{|c|}{ Multivariate analysis* } \\
\hline & n & $\%$ & $\mathrm{n}$ & $\%$ & $\overline{O R}$ & $95 \% \mathrm{Cl}$ & p value & $\overline{\text { OR }}$ & $95 \% \mathrm{Cl}$ & $\mathrm{p}$ value \\
\hline \multicolumn{11}{|l|}{ Usual practice } \\
\hline No & 36 & 23 & 209 & 34 & ref & & & ref & & \\
\hline Yes & 119 & 77 & 411 & 66 & 1.95 & 1.25 to 3.06 & $<0.01$ & 1.47 & 0.62 to 3.50 & 0.38 \\
\hline \multicolumn{11}{|c|}{ Last/reference sleep period } \\
\hline No & 106 & 70 & 280 & 45 & ref & & & ref & & \\
\hline Yes & 45 & 30 & 355 & 55 & 0.34 & 0.22 to 0.50 & $<0.001$ & 0.10 & 0.03 to 0.31 & $<0.001$ \\
\hline \multirow{2}{*}{\multicolumn{11}{|c|}{ Change in routine soother use during last/ref sleep period }} \\
\hline No & 80 & 53 & 495 & 81 & & & & & & \\
\hline Yes & 70 & 47 & 119 & 19 & 4.53 & 2.92 to 7.01 & $<0.001$ & 5.83 & 2.37 to 14.36 & $<0.001$ \\
\hline
\end{tabular}

*Adjusted for maternal age, education, smoking and drinking during pregnancy, social disadvantage, z scores for weight by gestation whether breast feeding was initiated at birth, baby being ill, crying/colic problems, symptoms in $48 \mathrm{~h}$ prior to last/reference sleep, tog of bed covering $\geqslant 10$, use of pillows, duvets, prone position, and co-sleeping during the last/reference sleep period.

use which presents a risk. Infants who were missing soothers were significantly more likely to have been co-sleeping during this same sleep period.

Maternal smoking during pregnancy is consistently associated with an increased risk of SIDS with a dose-response effect apparent implying a causal role..$^{353334}$ In this study co-sleeping infants were significantly more likely than non co-sleeping infants to have mothers who smoked during pregnancy and to be from socially disadvantaged backgrounds. In fact a total of $90 \%$ of all SIDS cases who were cosleeping during the last sleep period had mothers who smoked during pregnancy. The interaction between maternal smoking and bed sharing was such that the combined risk from both was greater than the sum of either risk factor alone (table 6). The mechanism by which maternal smoking exerts a fetal biological effect is generally thought to be via impaired fetal growth and chronic hypoxia. Maternal smoking has been shown to cause fetal brain stem gliosis, which could lead to impaired brain stem function and poorer cardiorespiratory control postnatally. ${ }^{35}{ }^{36}$ Thermal stress is thought to be one mechanism by which co-sleeping may put infants at risk; co-sleeping infants have been shown to have higher rectal temperatures than infants sleeping on their own ${ }^{37}$ The high tog value of adult bedding, the additional body heat of adjacent adults, and the potential covering of the infant's head with bedclothes are all factors associated with cosleeping which may lead to overheating of the infant..$^{38}$ Thus the combination of maternal smoking during pregnancy and co-sleeping postnatally, by presenting a thermally challenging situation, to a physiologically vulnerable infant, might prove a lethal combination to an infant unable to combine the circulatory demands of heat dissipation while maintaining an adequate central venous return. Recorded SIDS deaths have suggested that circulatory failure is a critical element in the sequence of events leading to death, ${ }^{39}$ and once again epidemiology may provide clues on further risk reduction measures.

\section{Authors' affiliations}

C McGarvey, M McDonnell, National Sudden Infant Death Register, Temple Street, Dublin 1, Republic of Ireland

A Chong, T Matthews, Department of Paediatrics, University College Dublin, Temple Street, Dublin 1, Republic of Ireland

M O'Regan, Department of Statistics, Trinity College Dublin, Dublin 2, Republic of Ireland

\section{REFERENCES}

1 Mehanni M, Cullen A, Kiberd B, et al. The current epidemiology of SIDS in Ireland. Ir Med J 2000;93:264-8

2 Mitchell EA, Tuohy PG, Brunt JM, et al. Risk factors for sudden infant death syndrome following the prevention campaign in New Zealand: a prospective study. Pediatrics 1997; 100:835-40.
3 Brooke H, Gibson A, Tappin D, et al. Case-control study of sudden infant death syndrome in Scotland. BMJ 1997;314:1516-20.

4 Kraus JF, Greenland S, Bulterys M. Risk factors for sudden infant death syndrome in the US Collaborative Perinatal Project. Int J Epidemiol 1989; 18:113-20.

5 Blair PS, Fleming PJ, Bensley D, et al. Smoking and the sudden infant death syndrome: results from 1993-5 case-control inquiry into stillbirths and deaths in infancy. BMJ 1996;313:195-8.

6 Hoffman HJ, Damus K, Hillman L, et al. Risk factors for SIDS: results of the National Institute of Child Health and Human Development SIDS Cooperative Epidemiological Study. Ann N Y Acad Sci 1988;533:13-30.

7 L'Hoir MP, Engelberts AC, van Well GT, et al. Case-control study of current validity of previously described risk factors for SIDS in the Netherlands. Arch Dis Child 1998;79:386-93.

8 Mitchell EA, Taylor BJ, Ford RPK, et al. Four modifiable and other major risk factors for cot death: The New Zealand study. J Paediatr Child Health 1992;28(suppl 1):S3-8.

9 Fleming PJ, Blair PS, Bacon C, et al. Environment of infants during sleep and risk of sudden infant death syndrome: results of 1993-5 case-control study for confidential inquiry into stillbirths and deaths in infancy. BMJ 1996;313:191-5.

10 Scragg RKR, Mitchell EA, Taylor BJ, et al. Bed sharing, smoking, and alcohol in the sudden infant death syndrome. BMJ 1993:307:1312-18.

11 Arnestad M, Andersen M, Vege $\AA$, et al. Changes in the epidemiological pattern of sudden infant death syndrome in southeast Norway, 1984-1998: implications for future prevention and research. Arch Dis Child 2001;85:108-15.

12 Takeda KA. A possible mechanism of sudden infant death syndrome (SIDS). $J$ Kyoto Pref Univ Med 1997;96:965-8.

13 Tasaki H, Yamashita M, Miyazaki S. The incidence of SIDS in Saga Prefecture (1981-1985). J Paediatr Assoc (Japan) 1988;92:364-8.

14 Lee NY, Chan YF, Davies DP, et al. Sudden infant death syndrome in Hong Kong: confirmation of low incidence. BMJ 1989;298:721-2.

15 Davies DP. Cot death in Hong Kong: a rare problem? Lancet 1985;2:1346-9.

16 ICCPS Study Group, Nelson EAS, Taylor BJ. International child care practices study: methods and study population. Early Hum Dev 1999;55:149-68.

17 Richard C, Mosko S, McKenna J, et al. Sleep position, orientation and proximity in bed sharing infants and mothers. Sleep 1996;19:685-90.

18 Mosko S, McKenna RC, Drummond S. Infant sleep architecture during bedsharing and possible implications for SIDS. Sleep 1996;19:677-84.

19 Kattwinkel J, Brooks JG, Keenan ME, et al. Changing concepts of sudden infant death syndrome: implications for infant sleeping environment and sleep position. Pediatrics 2000;105:650-6.

20 Tin W, Wariyar UK, Hey EN. Selection biases invalidate current low birthweight weight-for-gestation standards. The Northern Neonatal Network. Br J Obstet Gynaecol 1997; 104:180-5.

21 Carroll-Pankhurst C, Mortimer EA. Sudden infant death syndrome, bedsharing, parental weight and age at death. Pediatrics 2001; 107:530-6.

22 McKenna JJ, Mosko SS, Richard CA. Bed sharing promotes breastfeeding. Pediatrics 1997;100(2 pt 1):214-19.

23 Alm B, Wennergren G, Norvenius SG, on behalf of the Nordic Epidemiological SIDS Study, et al. Breastfeeding and the sudden infant death syndrome in Scandinavia, 1992-95. Arch Dis Child 2002;86:400-2.

24 McVea KL, Turner PD, Peppler DK. The role of breastfeeding in sudden infant death syndrome. J Hum Lact 2000;16:13-20.

25 Ponsonby A-L, Dwyer T, Gibbons LE, et al. Factors potentiating the risk of sudden infant death syndrome associated with the prone position. N Engl J Med 1993;329:377-82.

26 Blair PS, Fleming PJ, Smith IJ, et al. Babies sleeping with parents: case-control study of factors influencing the risk of sudden infant death syndrome. BMJ 1999;319:1457-62.

27 Beal SM, Byard RW. Sudden infant death syndrome in South Australia 19681997. Part 3: Is bed sharing safe for infants? J Paediatr Child Health 2000;36:552-4. 
28 Gessner BD, lves GC, Perham-Hester KA. Association between sudden infant death syndrome and prone sleep position, bed sharing, and sleeping outside an infant crib in Alaska. Pediatrics 2001;108:923-7.

29 Flick L, White DK, Vemulapalli C, et al. Sleep position and the use of soft bedding during bed sharing among African American infants at increased risk of sudden infant death syndrome. J Pediatr 2001;138:338-43.

30 Mitchell EA, Thach BT, Thompson JM, et al. Changing infants' sleep position increases risk of sudden infant death syndrome. New Zealand Cot Death Study. Arch Pediatr Adolesc Med 1999;153:1136-41.

31 Mitchell EA, Taylor BJ, Ford RP, et al. Dummies and the sudden infant death syndrome. Arch Dis Child 1993;68:201-4.

32 L'Hoir MP, Engelberts AC, van Well GT, et al. Risk and preventive factors for cot death in the Netherlands, a low-incidence country. Eur J Pediatr 1998;157:681-8.

33 McDonnell M, Mehanni M, McGarvey C, et al. Smoking: the major risk factor for SIDS in Irish infants. Ir Med J 2002;95:111-13.
34 Hauck FR. Changing epidemiology. In: Byard RW, Krous HF, eds. Sudden infant death syndrome. problems, progress \& possibilities. London: Arnold, 2001:31-57.

35 Lewis KW, Bosque EM. Deficient hypoxia awakening response in infants of smoking mothers: possible relationship to sudden infant death syndrome. J Pediatr 1995;127:691-9.

36 Storm H, Nylander G, Saugstad OD. The amount of brainstem gliosis in sudden infant death syndrome (SIDS) victims correlates with maternal cigarette smoking during pregnancy. Acta Paediatr 1999:88:13-18.

37 Tufnell CS, Petersen SA, Wailoo MP. Higher rectal temperatures in cosleeping infants. Arch Dis Child 1996;75:249-50.

38 Guntheroth WG, Spiers PS. Thermal stress in sudden infant death: is there an ambiguity with the rebreathing hypothesis? Pediatrics 2001; 107:693-8.

39 Harper RM. Sudden infant death syndrome; a failure of compensatory cerebellar mechanisms? Pediatr Res 2000;48:140-2.

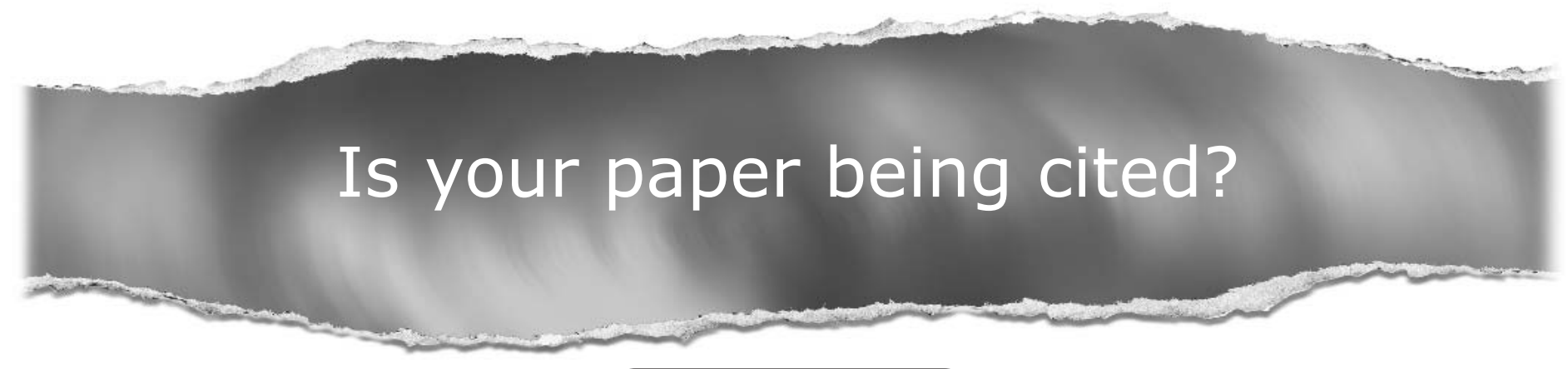

\section{CiteTrack service}

CiteTrack will alert you by email whenever new content in Archives of Disease in Childhood or a participating journal is published that matches criteria you want to track

Topics: Tell CiteTrack which words or subjects to watch for in new content Authors: Be alerted whenever key authors you are following publish a new paper Articles: Know whenever a paper of interest to you is referenced by another paper

\section{www.archdischild.com}

